J. Lake Sci. (湖泊科学), 2012, 24(3): 400-408

http: //www. jlakes.org. E-mail : jlakes@niglas.ac.cn

(C) 2012 by Journal of Lake Sciences

\title{
洱海硅藻群落结构的时空分布及其与环境因子间的关系”
}

\author{
胡竹君 ${ }^{1,2}$, 李艳玲 $^{1 * *}$, 李嗣新 ${ }^{3}$ \\ ( 1 : 中国科学院南京地理与湖泊研究所湖泊与环境国家重点实验室,南京 210008) \\ (2: 中国科学院研究生院,北京 100049 ) \\ ( 3 : 水利部中国科学院水工程生态研究所,武汉 430079)
}

\begin{abstract}
摘 要: 于 2004-2005 年间对洱海水体的硅藻群落进行逐月监测及研究, 共发现 71 个种, 分属于 18 个属. 硅藻群落结构 的季节变化显著, 主要优势种为耐营养的属种. 不同季节的硅藻优势种类有明显区别, 冬季的主要优势种为 Fragilaria crotonensis, 春季 Aulacoseira ambigua 与 $F$. crotonensis 的组合占优势地位, 夏季以 Cyclotella ocellata 为主,秋季则 A. ambigua 与 Cyclostephanos dubius 组合为优势种. 空间上除 $1^{\#}$ 点外, 硅藻分布虽然在相对丰度上存在一定的南北差异, 但优势属种在全 湖具有较好的一致性. 说明洱海全湖的水质都已处于中富营养状态. 对除 $1^{\#}$ 点外的 11 个采样点的硅藻及水化学数据进 行平均, 得到逐月数据, 通过数理统计分析的手段, 探讨硅藻群落变化与环境因子之间的关系, 结果表明影响季节尺度硅 藻群落发生变化的最主要因子是气象条件,其次是营养盐.
\end{abstract}

关键词: 硅藻; 群落结构;环境因子;先余分析;洱海

\section{Spatial and temporal distributions of diatom communities and their relationships with envi- ronmental factors in Lake Erhai}

\author{
HU Zhujun ${ }^{1,2}$, LI Yanling ${ }^{1} \&$ LI Sixin ${ }^{3}$ \\ (1: State Key Laboratory of Lake Science and Environment, Nanjing Institute of Geography and Limnology, Chinese Academy \\ of Sciences, Nanjing 210008 , P. R. China) \\ (2: Graduate University of Chinese Academy of Sciences, Beijing 100049, P. R. China) \\ (3: Institute of Hydroecology Ministry of Water Resource and Chinese Academy of Sciences, Wuhan 430079, P. R. China)
}

\begin{abstract}
A total of 71 diatom species belonging to 18 genera were indentified from Lake Erhai in Yunnan Province ( Southwest China) from February 2004 to January 2005. Results revealed a distinct seasonal succession of diatom communities, which dominated by eutrophic-tolerant species. Dominant species were different in each season: Fragilaria crotonensis was the main species in winter; Aulacoseira ambigua and F. crotonensis in spring; Cyclotella ocellata in summer; and A. ambigua and Cyclostephanos dubius in autumn. Except $1^{\#}$, the dominant diatom species were almost same in the whole lake, with a little difference in percentage between the north and the south part of the lake. It may suggest that the water quality of the whole lake was moderate to heavily polluted. Average monthly data of the diatom and water chemistry of all the sampling sites except $1^{\#}$ and the RDA analysis showed that meteorological condition was the key factor, and the nutrient was the second.
\end{abstract}

Keywords: Diatom; community structure; environmental factors; RDA; Lake Erhai

洱海位于大理市境内,对大理地区的发展起着重要作用. 自洱海 1996 年和 2003 年发生蓝藻水华以来, 富营养化和水污染的治理成为人们关注的焦点 ${ }^{[1-5]}$. 许多学者对洱海底泥和水体中的氮、磷等污染物的分布 规律, 沉水植被的分布变化,生物群落的历史演化及蓝藻的多样性和种群动态等进行了研究报道 ${ }^{[6-10]}$,但对 于洱海水体中的硅藻鲜有关注. 大量研究表明硅藻是水体中重要的初级生产者,对环境因子变化十分敏感,

* 国家自然科学基金项目(40972114) 资助. 2011-05-16 收稿;2011-06-17 收修改稿. 胡竹君,女,1986 年生,博士 研究生;E-mail: huzhujun86@163.com.

** 通信作者;E-mail :ylli@ niglas. ac. cn. 
被广泛用于水质监测, 指示水体环境 ${ }^{[11]}$. 因此, 本研究于 2004 年 2 月- 2005 年 1 月, 对洱海硅藻群落结构变 化做了详细的调查研究, 旨在探讨洱海水体硅藻季节变化的规律、空间分布的特点及其与水环境和气候变 化的关系,为研究洱海水体富营养化提供依据.

\section{1 材料与方法}

\section{1 研究区域概况}

洱海 $\left(25^{\circ} 36^{\prime} \sim 25^{\circ} 58^{\prime} \mathrm{N}, 100^{\circ} 06^{\prime} \sim 100^{\circ} 28^{\prime} \mathrm{E}\right)$ 位于大理白族自治州中部, 属澜沧江流域黑惠江支流的构 造断陷湖泊, 是云贵高原第二大淡水湖. 洱海水域北起大理市江尾乡, 南至下关镇, 南北长 $42.5 \mathrm{~km}$, 东西宽 $5.9 \mathrm{~km}$, 面积 $249.8 \mathrm{~km}^{2}$, 最大水深 $21.3 \mathrm{~m}$, 平均水深 $10.6 \mathrm{~m}$. 湖水依赖地表径流和湖面降水补给, 人湖河流 共 117 条, 主要河流有 23 条, 洱海东接凤尾阱, 西汇苍山十八溪水, 南纳波落江, 北承弥直河、永安江、罗时江, 西洱河是洱海惟一的天然出湖河流. 湖区属中亚带高原季风气候, 年平均气温 $15^{\circ} \mathrm{C}$, 年均降水量 $1056.6 \mathrm{~mm}$, 径 流的年内变化主要受气候因素的影响, 雨季 5-10 月径流量占年径流量的 $65 \%$ 以上 $^{[12]}$.

\section{2 样点采集与分析}

根据洱海的水体形态设置了 12 个采样点 (图 1), $1^{\#} \sim 12^{\#}$ 采样点水深分别为: $4.0 、 11.0$ 、 $6.0 、 8.0 、 13.0 、 7.5 、 4.0 、 8.0 、 9.0 、 8.0 、 9.0$ 、 $8.0 \mathrm{~m}$.

使用采水器对水样进行每月采集. 根据各 样点水深情况, 对各点水样进行相应深度的采 集 $(0 、 5 、 10 \mathrm{~m})$, 然后混匀, 取 $500 \mathrm{ml}$ 混合样品 带回实验室, 按照《地表水环境要素观测与分 析》标准方法 ${ }^{[13]}$ 测定理化指标, 主要包括总氮 $(\mathrm{TN})$, 总溶解性氮 ( TDN), 硝态氮 $\left(\mathrm{NO}_{3}^{-}-\mathrm{N}\right)$, 亚 硝态氮 $\left(\mathrm{NO}_{2}^{-}-\mathrm{N}\right)$, 铵态氮 $\left(\mathrm{NH}_{4}^{+}-\mathrm{N}\right)$, 总磷 $(\mathrm{TP})$, 总溶解磷 ( TDP), 磷酸根磷 $\left(\mathrm{PO}_{4}^{3-}-\mathrm{P}\right)$ 及 叶绿素 a(Chl. a) 含量. 另取 $500 \mathrm{ml}$ 混合水样加 人鲁哥氏液固定, 回到实验室后沉淀浓缩至 $25 \mathrm{ml}$, 倒人烧杯中, 静置 $24 \mathrm{~h}$, 用吸管将上清液 吸出, 下层浓缩液加热至 $90^{\circ} \mathrm{C}$, 加人 $30 \%$ 的 $\mathrm{H}_{2} \mathrm{O}_{2}$ 去有机质, 待反应完全后, 用蒸馏水清洗 3 次, 然后定量制片 ${ }^{[14]}$. 硅藻属种的鉴定主要依 据 Krammer 等 ${ }^{[15]}$ 的分类系统, 使用 OLYMPUS BX-51 显微镜 $(\times 1000)$ 进行鉴定, 对每个样品 至少鉴定 500 粒硅藻. 硅藻数据表示为相对丰 度 $(\%)$ 和丰度 $($ cells $/ \mathrm{L})$.

气象数据来自于大理气象站, 包括气温 (T)、降水 (rainfall)、风速 (wind velocity) 和日照 时数 (sunshine duration).

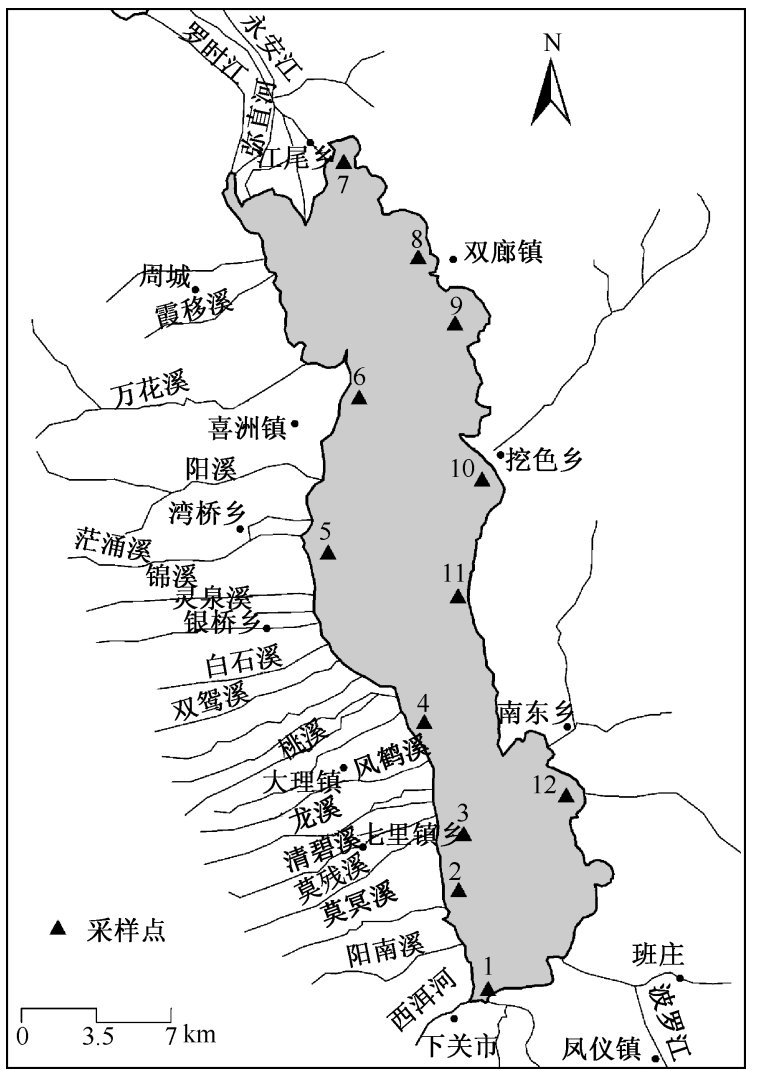

图 1 洱海水样采样点

Fig. 1 Sampling sites of Lake Erhai

\section{3 数据统计分析}

分层聚类分析 (HCA) 是聚类分析中应用最为广泛的探索性方法, 其实质是根据观察值或变量之间的亲 疏程度, 以逐次聚合的方法, 将最相似的对象结合在一起, 直到聚成一类 ${ }^{[16]}$. 本文将各采样点 12 个月的硅藻 含量进行平均得到各个点的硅藻含量的年均值, 用此均值来进行硅藻组合时空相似性的分层聚类分析, 采 用的计算方法是欧式距离法, 聚类方法为组间关联. 上述分析在 SPSS 18.0 中运行.

文中采用线性回归的圥余分析 (Redundancy Analyses, RDA) 研究环境因子对硅藻组合变化的影响. 
$\mathrm{RDA}$ 是一种直接梯度分析方法, 能从统计学的角度来评价一个或一组变量与另一组多变量数据之间的相互 关系 ${ }^{[17-18]}$. 将除 $1^{\#}$ 点外的 11 个样点的硅藻和水化学数据进行平均, 得到逐月的数值. 硅藻属种数据作为解 释变量, 本文选择至少在 2 个样品中出现, 含量至少在 1 个样品中超过 $1 \%$ 的常见属种进行数值分析, 11 个 样品中共有 11 个主要硅藻属种用于分析, 属种数据用平方根进行转换. 将湖泊水化学数据和气象数据作为 $\mathrm{RDA}$ 分析中的响应变量, 气象数据包括气温、降水、风速和日照时数, 水环境数据包括 $\mathrm{TN} 、 \mathrm{TDN} 、 \mathrm{NO}_{3}^{-}-\mathrm{N}$ 、 $\mathrm{NO}_{2}^{-}-\mathrm{N} 、 \mathrm{NH}_{4}^{+}-\mathrm{N} 、 \mathrm{TP} 、 \mathrm{TDP} 、 \mathrm{PO}_{4}^{3-}-\mathrm{P} 、 \mathrm{Chl}$. a, 大于 10 且小于 100 的数值进行开平方处理, 大于 100 的取其对数. 因上述响应变量中可能存在高度自相关的变量, 因此需要剔除膨胀系数大于 20 的变量, 之后用剩余变量来 分析影响硅藻种群变化的份额 ${ }^{[18]}$, 通过进一步选择 ( forward selection) 和蒙特卡罗检验 (Monte Carlo permutation test $)(P<0.05, n=999)$ 得到解释硅藻群落变化的显著变量. 最后对得到的显著变量进行进一步的检 验, 使用 Bonferroni correction 方法对显著性 $P$ 的临界值重新选择, 即用 $0.05 /(n+1)$ 来界定 ${ }^{[19]}$. 上述统计分 析在程序 CANOCO 4.5 版本中运行.

两变量间的相关可以用许多统计值来测量, 最常用的是皮尔森相关系数, 它是一种线性相关系数. 本文 的皮尔森相关系数在 Origin 8.0 中运算得到.

\section{2 结果}

\section{1 硅藻群落的种类组成及主要优势种的季节变化}

本研究共鉴定硅藻 71 种分属于 18 属, 从相对丰度图谱 (图 2) 可以看出,2004 年 2-4 月主要优势种为 Fragilaria crotonensis $(67 \% \sim 92 \%)$, 伴生种为 Aulacoseira ambigua、A. granulata、Cyclotella comta、Cyclostephanos dubius 和 Stephanodiscus hantzschii. 5-12 月 F. crotonensis 一直呈减少的趋势 ( $2 \% \sim 44 \%), 5-7$ 月 A. ambigua增加成为主要优势种 $(30 \% \sim 67 \%)$, Cyclostephanos cf dubius 也在 5-8 月间增加 ( $2 \% \sim 19 \%)$, Cyclotella ocellata 在 7-9 月丰度较高, 尤其在 8 月成为优势种 (73\%), 而后又呈减少趋势, A. granulata 在 9

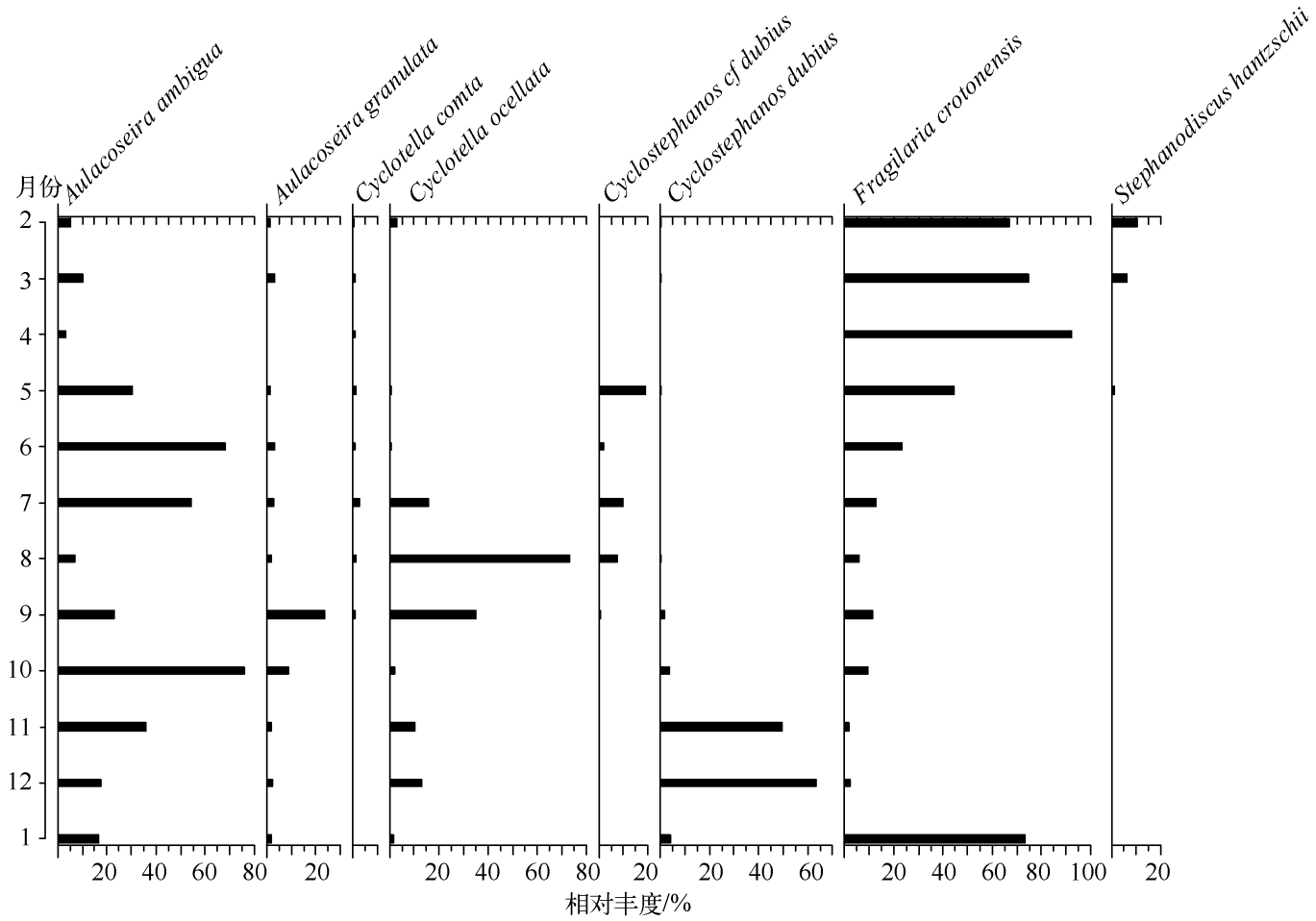

图 2 洱海 12 个采样点平均的逐月硅藻相对丰度图谱

Fig. 2 Average relative abundance of diatom species from 12 sampling sites in Lake Erhai 


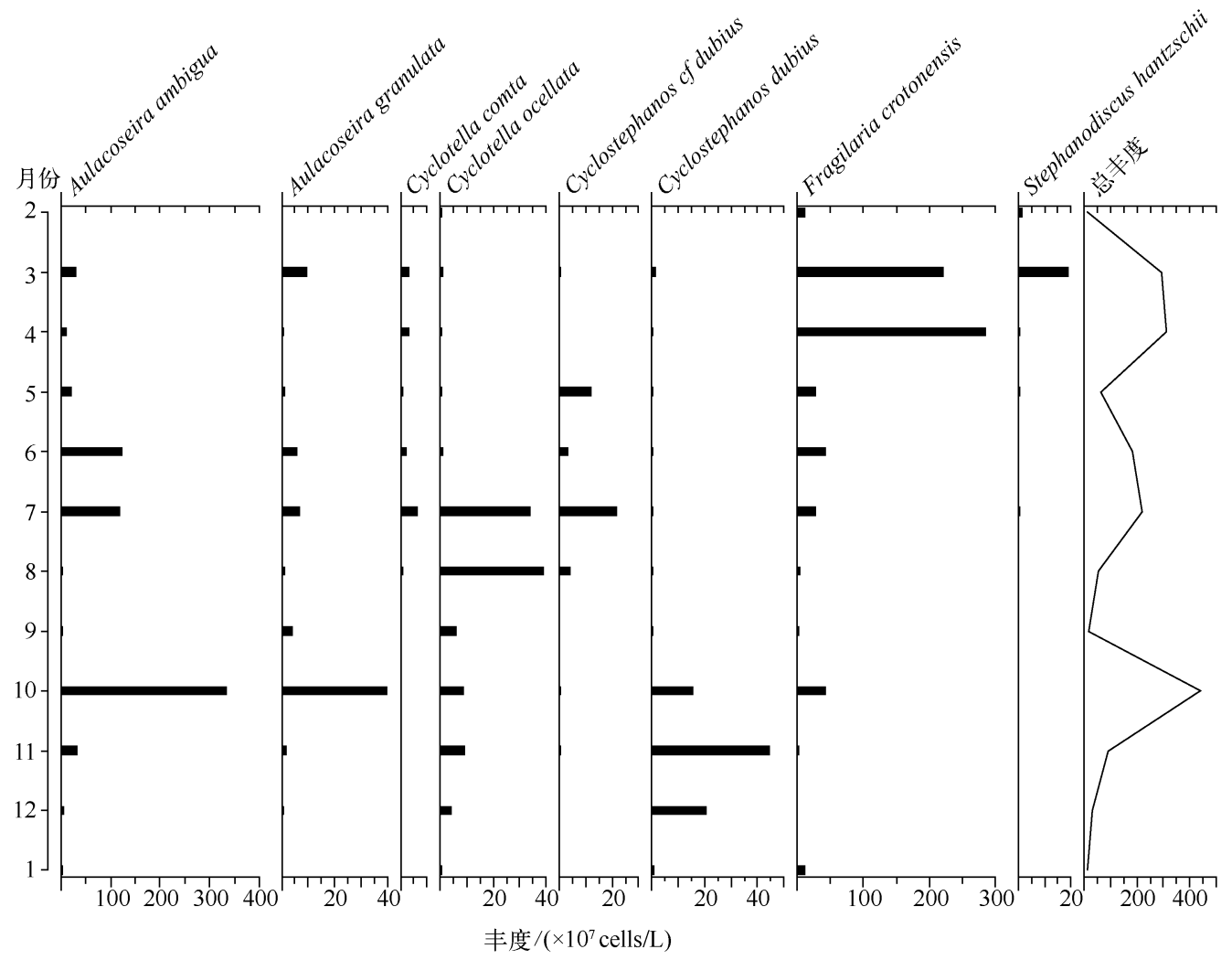

图 3 洱海 12 个采样点平均的逐月硅藻丰度图谱

Fig. 3 Concentration of diatom species from 12 sampling sites in Lake Erhai

月达到峰值 $23 \%, 10$ 月时 A. ambigua 再度成为优势种 (75\%), 而在 $11-12$ 月被 C. dubius 所取代 ( $49 \%$ $63 \%), 2005$ 年 1 月 F. crotonensis 又重新占据优势地位 (73\%). 从以上分析可以得出, 洱海的年际硅藻组合 分布具有明显的季节性, 春季( $2-4$ 月) 和晚冬 (1 月) 主要为 F. crotonensis, 初夏 (5-7 月) 主要为 A. ambig$u a$ 和 $F$. crotonensis, 盛夏 $(8-9$ 月) 优势种是 $C$. ocellata, 晚秋至冬季 $(10-12$ 月) 则是 A. ambigua 和 C. dubius 先后成为优势种. 而硅藻丰度在 10 月出现最 大峰值, 4 月次之, 冬季硅藻丰度最低.

而丰度图谱 (图 3 ) 与相对丰度图谱相比有所差 异. F. crotonensis 在 3、4 月份浓度最高, A. ambigua 和 A. granulata 在 10 月份都达到年内最高值, $6 、 7$ 月份次 之. C. ocellata 则在 7、8 月份丰度较高.

\section{2 硅藻群落的时空分布特征}

在 SPSS 中用分层聚类的方法得到, 12 个采样点 的硅藻群落时空分布主要可以分为 2 大类 (图 4), $1^{\text {\# }}$ 点单独为 1 类 (I ), 剩下的 11 个点为一类. 这 11 个 点又可以分为两组, 位于洱海南部湖区的 $2^{\#} \sim 5^{\#}$ 点和

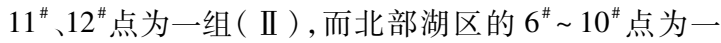
组 (III), 也就是除 $1^{\#}$ 点外, 以 $5^{\#}$ 点为界, 南北各为 一组.

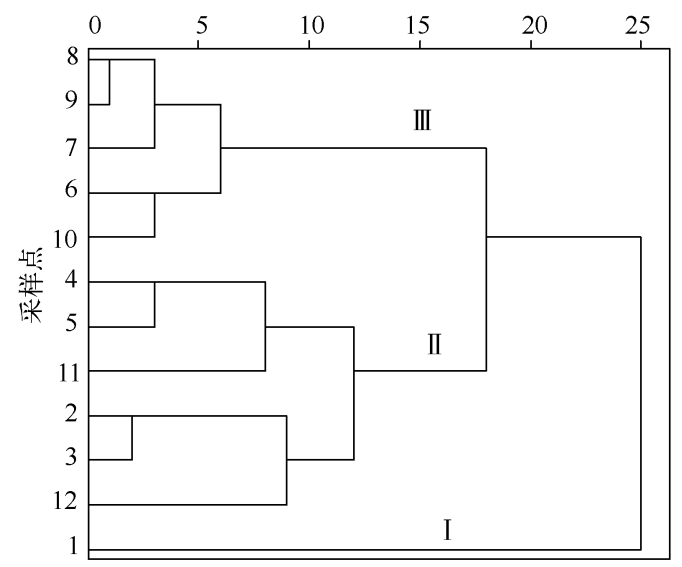

图 4 洱海硅藻群落分层聚类树状图

Fig. 4 Cluster tree plot of diatom communities in Lake Erhai 
从硅藻图谱(图 5)来看, I 区 (1 号点)的 2 月和 3 月的优势种为 $S$. hantzschii, 而另 2 个区的采样点该 时期的优势种均为 F. crotonensis. 总体而言, II 区和 III 区在各个月份的优势种基本一致,但各优势种的相对 丰度有所区别, 例如, 在 5-7 月以及 9 月和 11 月, A. ambigua 在 II 区的相对丰度比 III 区要高, 而 III 区的 $C$. dubius 和 C. ocellata 分别在 $11-12$ 月和 8 月都高于 II 区.

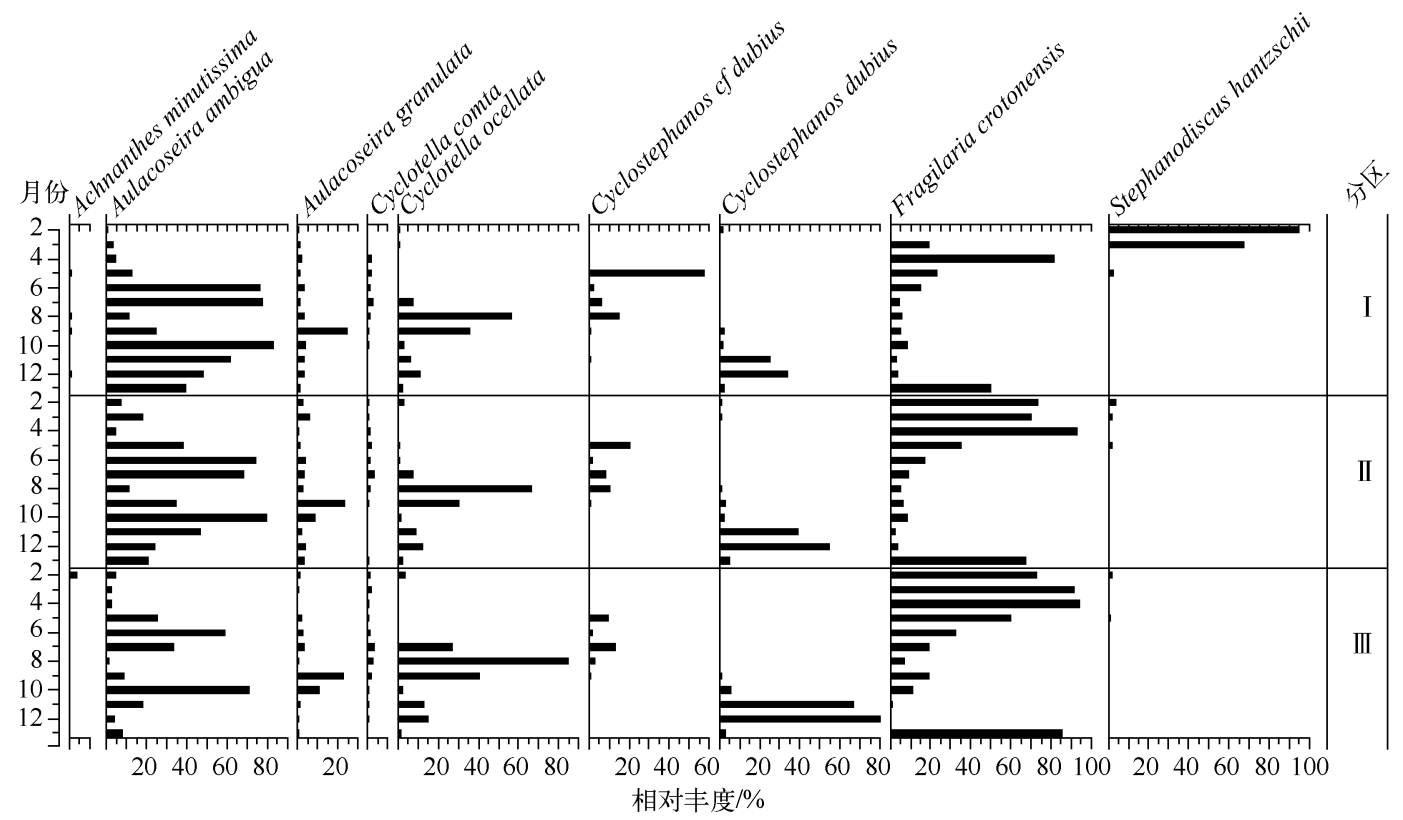

图 5 三个分组的硅藻属种相对丰度图谱(每个分组包括的样点参见图 3)

Fig. 5 Relative abundance of diatom species from the three groups

\section{3 环境因子}

2004 年 2 月到 2005 年 1 月日照时数在 $3.2 \sim 8.5 \mathrm{~h}$ 之间, 其中 7 月和 9 月最短, 由于该时期为雨季, 因 此日照时间减少, 日照时间以 2-3 月及 2004 年 11 月到 2005 年 1 月较高, 在 $7 \sim 8 \mathrm{~h}$ 左右. 12 月温度最低为 $8^{\circ} \mathrm{C}$, 最高温度出现在 6-8 月, 平均在 $19^{\circ} \mathrm{C}$ 左右. 大理的 5-9月为雨季, 月降水量在 $124 \sim 230 \mathrm{~mm}$ 之间, 而在 这期间以 6 月的降水量相对较低. 风速在 2004 年 2-5 月及 2005 年 1 月较大, 在 $3 \mathrm{~m} / \mathrm{s}$ 以上, $4-5$ 月及 $11-$ 12 月风速在 $2 \sim 3 \mathrm{~m} / \mathrm{s}$ 之间, 其余月份小于 $2 \mathrm{~m} / \mathrm{s}$. 从全湖 12 个采样点平均得到的逐月水化学数据来看, $\mathrm{TN}$ 从 2-4 月呈增长趋势, 在 4 月达到年内的最高值 $(497 \mu \mathrm{g} / \mathrm{L})$, 之后缓慢下降, 12 月浓度最低. TN 的均值为 $434 \mu \mathrm{g} / \mathrm{L}$, TDN 与 TN 总体趋势一致, 但在 6 月达到最高值 $(432 \mu \mathrm{g} / \mathrm{L})$. TP 与 TDP 的变化趋势相似, 最高值 都出现于 5 月, 分别为 56 和 $48 \mu \mathrm{g} / \mathrm{L}$ (图 6). $\mathrm{TP}$ 的均值为 $38 \mu \mathrm{g} / \mathrm{L}$.

\section{$2.4 \mathrm{RDA}$ 分析}

$\mathrm{RDA}$ 分析的结果表明气象条件的变化对洱海水体硅藻群落演替的作用最显著, 其次是湖泊的营养盐条 件. RDA 的第一轴和第二轴共解释了 $48 \%$ 的硅藻变率. 经过蒙特卡罗检验后得到的显著因子为风速和总溶 解氮, 它们分别独立解释了 $23 \%$ 和 14\% 的变率(图 7), 并且这两个变量都通过了 Bonferroni correction 的检 验, $P$ 值分别为 0.012 和 0.024 .

为检验主要的硅藻属种与气象和水化学因子的关系, 用全湖除 $1^{\#}$ 点外 11 个点平均的属种数据与水化 学数据及气象数据进行了皮尔森相关性检验, 分析表明 A. ambigua 与 $\mathrm{NH}_{4}^{+}-\mathrm{N}$ 呈显著负相关, 与叶绿素 a 含

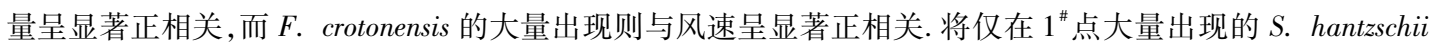

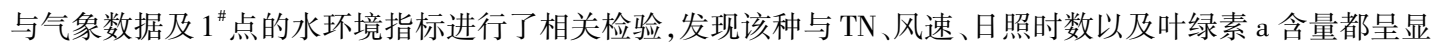
著正相关(表 1 ). 


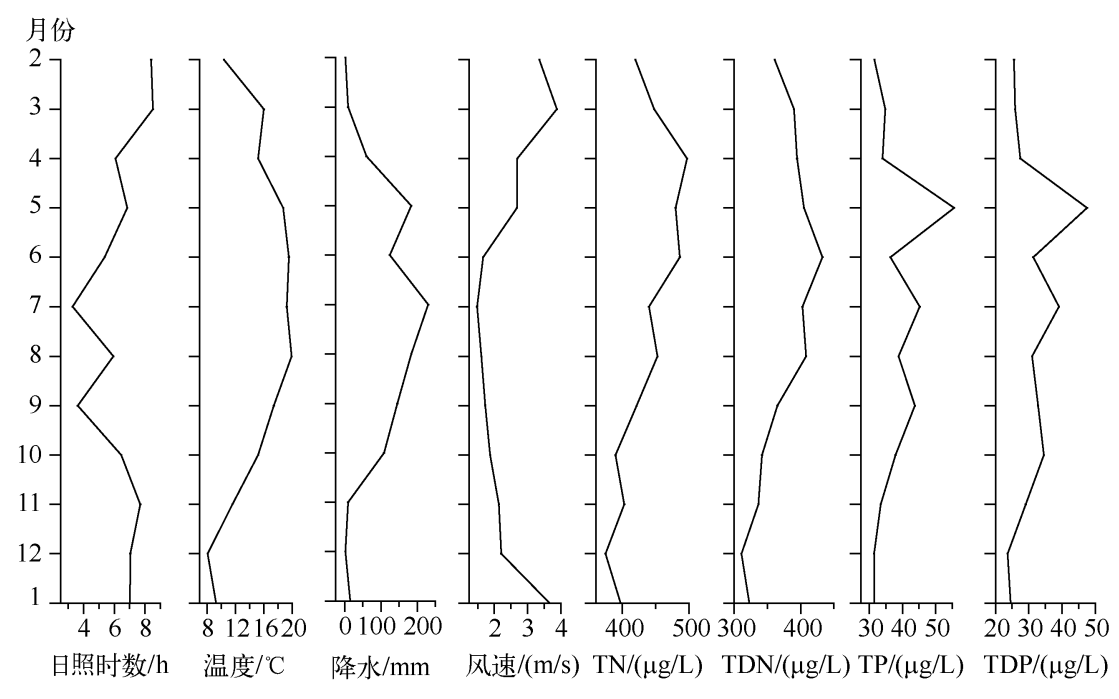

图 6 洱海主要的环境因子

Fig. 6 Main environmental factors from Lake Erhai

表 1 三个硅藻主要优势种与湖泊水化学和气象变量的皮尔森相关系数

Tab. 1 Correlation coefficients of three dominant diatom species and limnology data, meteorological data

\begin{tabular}{ccccc}
\hline 指标 & 变量 & A. ambigua & F. crotonensis & S. hantzschii \\
\hline 湖泊水环境 & $\mathrm{TN}$ & 0.04 & 0.19 & $0.68^{*}$ \\
& $\mathrm{TDN}$ & 0.19 & 0.05 & 0.44 \\
& $\mathrm{NO}_{3}^{-}-\mathrm{N}$ & -0.02 & 0.07 & 0.43 \\
& $\mathrm{NO}_{2}^{-}-\mathrm{N}$ & -0.02 & -0.07 & 0.34 \\
& $\mathrm{NH}_{4}^{+}-\mathrm{N}$ & $-0.74^{*}$ & 0.48 & -0.37 \\
& $\mathrm{TP}$ & 0.33 & -0.31 & 0.06 \\
& $\mathrm{TDP}$ & 0.49 & -0.30 & -0.16 \\
& $\mathrm{PO}_{4}^{3-}-\mathrm{P}$ & -0.02 & 0.30 & 0.44 \\
& $\mathrm{Chl.}^{\text {气象条件 }}$ & $0.59^{*}$ & -0.42 & $0.84^{*}$ \\
& 气温 & 0.36 & -0.17 & -0.25 \\
& 风速 & -0.55 & $0.84^{*}$ & $0.64^{*}$ \\
& 降水 & 0.47 & -0.26 & -0.45 \\
& 日照时数 & -0.38 & 0.43 & $0.58^{*}$ \\
\hline
\end{tabular}

*表示差异显著, $P<0.05$.

\section{3 讨论}

洱海水体中的主要优势种如 A. ambigua、A. granulata、C. dubius 和 S. hantzschii 在长江中下游富营养湖 泊中也属于常见种 ${ }^{[20]}$, 在太湖、巢湖、东湖等的研究中均有记录 ${ }^{[21-22]}$. Kirilova 等研究了荷兰 8 个深水富营养 湖泊, 认为这些湖泊中普遍分布的 C. ocellata、A. granulata、C. dubius 和 S. hantzschii 也指示了中营养到富营 养的水体条件 ${ }^{[23]}$. Ellen van Donk 等提出 $S$. hantzschii 喜高 $\mathrm{N}$ 水体 ${ }^{[24]}$. 由上述分析结果可知, 在洱海中 S. hantzschii与 $\mathrm{TN}$ 也有较好的相关性(表 1). 根据 Interlandi 等的研究结果表明 $F$. crotonensis 在水体 $\mathrm{N}$ 含量 高而 $\mathrm{P}$ 含量相对较低时, 比其它许多种类更有优势 ${ }^{[25-26]}$. 并且在一些高山 $\mathrm{N}$ 限制湖泊的研究中, 也认为 $F$. crotonensis 指示了水体中 $\mathrm{N}$ 的富集 ${ }^{[27-28]}$. 由此, 从硅藻群落结构上可以推测洱海在 2004 年 2 月至 2005 年 1 


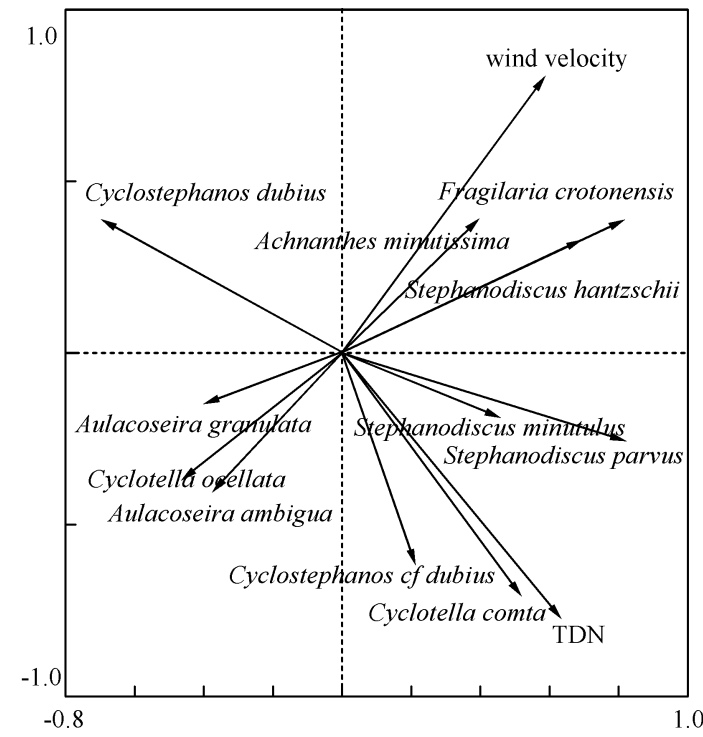

图 7 洱海硅藻与环境数据的 RDA 分析结果

Fig. 7 The result of RDA using dialom and average sites data in Lake Erhai
月的水质状况为 $\mathrm{N}$ 含量较高, 而 $\mathrm{P}$ 含量较低, 为中 营养到富营养的水体.

而 2004 年 2 月一 2005 年 1 月洱海 TP 均值为 38 $\mu \mathrm{g} / \mathrm{L}, \mathrm{TN}$ 均值为 $434 \mu \mathrm{g} / \mathrm{L}$, 与 2004 年的调查结 果 ${ }^{[29]}$ 一致. 按照中国水质指标的营养分类标准 ${ }^{[30]}$, 当总磷指标在 $10 \sim 50 \mu \mathrm{g} / \mathrm{L}$ 范围内, 湖泊为中营养 状态, 因此洱海在 2004 年 2 月一 2005 年 1 月期间水 质呈中营养水平. 洱海水体 $\mathrm{N}$ 含量高而 $\mathrm{P}$ 含量相对 较低, 这与硅藻属种生活习性推测的湖水特征相一 致. 从历史数据来看, $1992-2001$ 年间洱海 $\mathrm{TN}$ 浓 度 $(220 \sim 380 \mu \mathrm{g} / \mathrm{L}) 、 \mathrm{TP}$ 浓度 $(14 \sim 30 \mu \mathrm{g} / \mathrm{L})$ 都呈上 升趋势, 洱海的富营养化程度有所增加, 处于中营养 向中富营养化转变阶段 ${ }^{[31]}$. 而到 2004 年, 洱海的 TN 和 TP 浓度较之过去又有所升高, 洱海可能已经 处于中营养的后期阶段.

从硅藻的空间分布来看, 由于 $1^{\#}$ 点的 $\mathrm{TP}$ (42 $\mu \mathrm{g} / \mathrm{L})$ 高于其它点 $(36 \sim 39 \mu \mathrm{g} / \mathrm{L})$, 而 $S . h a-$ ntzschii 需要的 $\mathrm{P}$ 含量比 F. crotonensis 要高 ${ }^{[25]}$, 这可 能导致该点出现异于其它点的 S. hantzschii 暴发.

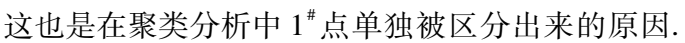

$1^{\#}$ 点位于洱海的出湖河西洱河的上游河口, 地处下关市, 厂区密集, 该点营养盐的偏高可能与该处的点源污

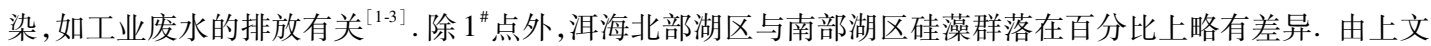
分析可知 A. ambigua 与 $\mathrm{NH}_{4}^{+}-\mathrm{N}$ 呈显著负相关关系, 而北部湖区 $\mathrm{NH}_{4}^{+}-\mathrm{N}$ 含量 $(71 \mu \mathrm{g} / \mathrm{L})$ 高于南部湖区 $(66 \mu \mathrm{g} / \mathrm{L})$, 这就解释了在 A. ambigua 为优势种的时期, 北部 ( III 区) 的相对含量明显低于南部 (II 区) 的原 因. 由于洱海流域北部地区主要以农业生产为主, 主要通过弥茸河、罗时江、永安江等向洱海排水, 而 $\mathrm{NH}_{4}^{+}-\mathrm{N}$ 主要来自于农业面源污染, 因此造成了 $\mathrm{NH}_{4}^{+}-\mathrm{N}$ 浓度呈现北高南低的特征 ${ }^{[7]}$. 但总体来看, 除了 $1^{\#}$ 点, 洱海全 湖的硅藻群落的优势属种具有较好的一致性,说明全湖的水质基本一致,都已处于中营养的状态.

有研究表明, 硅藻的季节分布模式与湖水混合和分层有直接关系, 而氮、磷和硅等营养物质的影响则占 次要地位, 春季和秋季水体混合时期以浮游和底栖种为主, 而夏季分层时期只有浮游种占绝对优势 ${ }^{[32]}$. 在洱 海, 2-5 月 F. crotonensis 是优势种, A. ambigua 在 6-7 月和 10 月占据优势地位, 11-12 月 C. dubius 成为优 势种, 在 8 月份主要优势种为 C. ocellata, A. ambigua 明显减少, 与上述研究结果相一致. Makullal 等在 Kellersee 湖和 Behler See 湖发现可溶解的活性硅含量减少是造成 A. ambigua 在分层时期之前迅速减少的原因 ${ }^{[32]}$. 另外, 分层时期没有垂直混合, 而 Aulancoseria 的壳体较重, 因此会很快地下沉到无光的环境中, 导致其生长 受到限制 ${ }^{[33]}$. 本文 RDA 分析的结果表明,洱海硅藻的季节演替的最主要驱动因子是风速, 在 2004 年 $2-5$ 月及 2005 年 1 月洱海地区风速较高, 会增强水体的混合. 而风速作为与分层密切相关的因子, 会对硅藻群落 产生间接的影响. 水体混合模式的改变, 会使水体光照条件发生变化, 进而影响藻类的丰度与繁殖速率 ${ }^{[34]}$. F. crotonensis 是广布种, 在晚冬及早春大量出现, 适应于 $\mathrm{N}$ 含量高的环境, 在本研究中与风速有很好的相关 性, 因此可以推测风速增大时, 有利于水体混合, 使营养物质 (如氮) 再悬浮于水体中, 促进了该种生长, 并且 该种为优势种的 2004 年 2-5 月及 2005 年 1 月,也是 TN 含量相对较高的时期.

\section{4 结论}

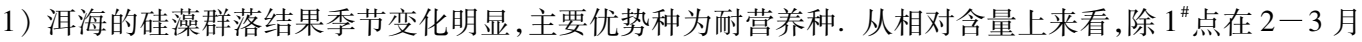
优势种为 $S$. hantzschii 外, 2004 年 2-4 月及 2005 年 1 月优势种为 F. crotonensis, 5 月 F. crotonensis 与 A. ambigua 同为优势种, 6-7 月及 10 月为 A. ambigua 占据优势地位, 8-9 月和 11-12 月的优势种则分别 
为 C. ocellata 和 C. dubius. 硅藻丰度峰值出现于 10 月份.

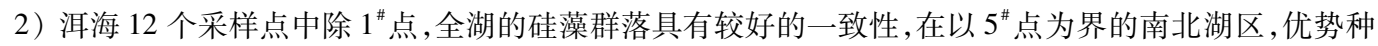
在百分比含量上略有差别.

3) 影响季节尺度的洱海水体硅藻群落结构变化的因素包括营养盐、风速及周边外来因素的阶段性影 响, 而其中气象因素对硅藻变率解释的份额最多, 营养盐次之, 说明在洱海影响硅藻群落季节性演替的因素 主要是气象条件变化.

致谢: 感谢刘恩峰老师和审稿人对本文的修改提出宝贵意见!

\section{5 参考文献}

[ 1 ] 潘红坌, 王云飞, 董云生. 洱海富营养化影响因素分析. 湖泊科学, 1999, 11(2) : 184-188.

[2 ］李杰君. 洱海富营养化探析及防治建议. 湖泊科学, 2001, 13(2) : 187-192.

[ 3 ] 彭文启, 王世岩, 刘晓波. 洱海流域水污染防治措施评估. 中国水利水电科学研究院学报, 2005, 3(2) : 95-99.

[4] 杨建云. 洱海湖区非点源污染与洱海水质恶化. 云南环境科学, 2004, 23: 104-106.

[ 5 ] 杨曙辉, 宋天庆. 洱海湖滨区的农业面源污染问题及对策. 农业现代化研究, 2006, 27 (6) : 428-432.

[6] 胡小贞, 金相灿, 杜宝汉等. 云南洱海沉水植被现状及其动态变化. 环境科学研究, 2005, 18(1): 1-4.

[7] 王世岩, 刘晓波, 刘 畅. 洱海表层水体中氮素空间变异分析. 水资源保护, 2010, 26(6) : 37-41.

[ 8 ] 李宁波, 李 原. 洱海表层沉积物营养盐的含量分布和环境意义. 云南环境科学, 2001, 20(1) : 26-27.

[ 9 ] 王 芸. 洱海夏秋季蓝藻种群动态变化及水华成因分析. 大理学院学报, 2008, 17(2) : 39-42.

[10］吕兴菊, 朱 江, 孟 良. 洱海水华蓝藻多样性初步研究. 环境科学导刊, 2010, 29(3): 32-35.

[11] Stoermer EF, Smol JP. The Diatoms: Applications for the environmental and earth sciences. Cambridge: Cambridge University Press, 2001.

[12］李 萍. 浅谈洱海地表水资源监测信息系统建设. 人民珠江, 2009, 6: 69-72.

[13] 谢贤群, 王立军. 水环境要素观测与分析. 北京: 中国标准出版社, 1999.

[14] Battarbee RW. Diatom analysis. In: Berglund BE ed. Handbook of holocene palaeoecology and palaeohydrology. Chichester: Wiley, 1986: 527-570.

[15] Krammer K, Lange-Bertalot H. Bacillariophyceae(1-4 Teil). In: Ettl H, Gerloff J, Heynig H et al eds. Süsswasserflora von Mitteleuropa. Stuttgart and Jena: Gustav Fischer Verlag, 1986-1991: 2(1/2/3/4).

[16] Zhou F, Liu Y, Guo HC. Application of multivariate statistical methods to the water quality assessment of the watercourses in the Northwestern New Territories, Hong Kong. Environmental Monitoring and Assessment, 2006, 10: 1007-1066.

[17] Borcard D, Legendre P, Drapeau P. Partialling out the spatial component of ecological variation. Ecology, 1992, 73: 1045-1055.

[18] Ter Braak CJF, Smilauer P. CANOCO regerencemanual and Cano Draw for Windows user s guide: Software for canonical community ordination (version 4.5). New York: Microcomputer Power, 2002.

[19] Cabin RJ, Mitchell RJ. To Bonferroni or not to Bonferroni: when and how are the questions. Bulletin of the Ecological Society of America, 2000, 81: 246-248.

[20] 董旭辉, 羊向东, 王 荣. 长江中下游地区湖泊富营养化的硅藻指示性属种. 中国环境科学, 2006, 26(5): 570-574.

[21] 陈 旭, 羊向东, 刘 倩等. 巢湖近代沉积硅藻种群变化与富营养化过程重建. 湖泊科学, 2010, 22 (4): 607-615.

[22] Yang XD, Anderson NJ, Dong XH et al. Surface sediment diatom assemblages and epilimnetic total phosphorus in large, shallow lakes of the Yangtze floodplain: their relationships and implications for assessing long-term eutrophication. Freshwater Biology, 2008, 53: 1273-1290.

[23] Kirilova EP, Cremer H, Heiri O et al. Eutrophication of moderately deep Dutch lakes duringthe past century: flaws in the expectations of water management? Hydrobiologia, 2010, 637: 157-171.

[24] Ellen van Donk E, Kilham SS. Temperature effects on silicon-and phosphorus-limited growth and competitive interactions among three diatoms. Journal of Phycology, 1990, 26: 40-50.

[25] Interlandi SJ, Kilham SS. Assessing the effects of nitrogen deposition on mountain waters: a study of phytoplankton com- 
munity dynamics. Water Science and Technology, 1998, 38: 139-146.

[26] Interlandi SJ, Kilham SS, Theriot EC. Responses of phytoplankton to varied resource availability in large lakes of the greater yellowstone ecosystem. Limnology and Oceanography, 1999, 44: 668-682.

[27] Wolfe AP, Van Gorp AC, Baron JS. Recent ecological and biogeochemical changes in alpine lakes of Rocky Mountain National Park (Colorado, USA) : a response to anthropogenic nitrogen deposition. Geobiology, 2003, 1(2): 153-168.

[28 ] Saros JE, Michel TJ, Interlandi SJ et al. Resource requirements of Asterionella formosa and Fragilaria crotonensis in oligotrophic alpine lakes: implications for recent phytoplankton community reorganizations. Canadian Journal of Fisheries and Aquatic Sciences, 2005, 62(7): 1681-1689.

[29］杨晓雪. 洱海总磷、总氮污染现状分析. 云南环境科学, 2006, 25 (增刊) : 113-115.

[30］金相灿, 刘鸿亮, 屠清瑛等. 中国湖泊的富营养化. 北京: 环境科学出版社, 1990: 614 .

[31] 韩 涛, 彭文启, 李怀恩等. 洱海水体富营养化的演变及其研究进展. 中国水利水电科学研究院学报, 2005,3 (1) : $71-78$.

[32] Makullal A, Sommerl U. Relationships between resource ratios and phytoplankton species composition during spring in five north German lakes. Limnology and Oceanography, 1993, 38(4) : 846-856.

[33] Reynolds CS. The ecology of freshwater phytoplankton. New York: Cambridge University, 1984 : 384.

[34] Koster D, Pienitz R. Seasonal diatom variability and paleolimnological inferences-a case study. Journal of Paleolimnolo$g y, 2006,35$ : 395-416. 